\title{
Suggested parameters to setup $Y$ chromosome microsatellites markers as a prostate cancer genetic risk indicator
}

\author{
Berjas Abumsimir ${ }^{1}$ (i) \& Moulay Mustapha Ennaji ${ }^{* 1}$ \\ ${ }^{1}$ Team of Virology, Oncology and Medical Biotechnology, Laboratory of Virology, Microbiology, Quality and Medical \\ Biotechnologies/Ecotoxicology and Biodiversity, Faculty of Sciences and Techniques - Mohammedia, Hassan II University of \\ Casablanca, PO BOX 146 Mohammedia 20650, Morocco \\ *Author for correspondence: Tel: +21 261748 862; m.ennaji@yahoo.fr
}

\begin{abstract}
"We suggest here to establish a PCa genetic risk evaluation system using the outputs of $Y$ chromosome marker studies such as populations' haplogroups and individual haplotypes."
\end{abstract}

First draft submitted: 2 April 2019; Accepted for publication: 6 June 2019; Published online: 20 August 2019

Keywords: genetic risk $\bullet$ microsatellites $\bullet$ prostate cancer $\bullet$ race $\bullet$ Y chromosome

This is a scientific preface to discuss using Y chromosome microsatellites as an indicator instead of prostate cancer genetic risk. For the first time, in this letter, we will explain the justification for using Y chromosome databases as prostate cancer genetic risk indicator, and the benefits of this linkage between $\mathrm{Y}$ chromosome microsatellites in one hand, and genetic risk of prostate cancer $(\mathrm{PCa})$ in the other hand.

Prostate cancer is a very common tumor, usually slow growing, and some types of prostate cancer could be more aggressive than other types. Age, family history and obesity are the factors that can increase the risk of prostate cancer among men. Looking at prostate victim statistics around the world - there was approximately 1.6 million incident cases of prostate cancer in 2015, in USA there were 190,000 new cases in 2016 [1], and in Sweden in 2016, about 10,500 men were diagnosed with prostate cancer and over 2300 men died [2]. In Japan, there were about 78,400 incidents and 12,400 projected cancer deaths in 2018 [3]. The incidences and mortalities statistics depend on population size, level of healthcare quality and early diagnosis activities. Within many risk factors causing prostate cancer, several studies revealed that race is one of the strong genetic risk factors. Regarding prostate cancer incidence and mortality, notable differences across racial and ethnic groups have been recorded. There is an acceptable consensus that the highest incidence rates of prostate cancer is found among men of African origin, and vice versa the lowest rates have been observed in Asia, especially in Japan and China [4-6].

Previously, epidemiological statistics were usually performed in a certain country, but given the difference in incident rates between origins, there has been a push to consider race as a risk factor. In multi-origin countries such as USA which is an ideal society to study race and different responses in prostate cancer in order to estimate incidents and mortality rates, studies confirmed prostate cancer more commonly affects black men than white or Hispanic men. In other countries, studies regarding PCa epidemiology ran in the same manner, especially mixed populations [7-9]. So by converting epidemiological studies into race standards, it will be the African origin men that have the highest degree of risk. In contrast, Japanese men and those of southeast origin will have the lowest degree of risk. Consequently, other races - for example, Caucasian and Europeans, have moderate-degree risk. This is the first impression when we look to PCa genetic risk from the race angle, but this conclusion should be expanded on and discussed further, regarding individuals' different responses against prostate tumor development. Before discussing this issue, we should note that we are talking about one factor among many genetic factors, with some consideration to other nongenetic factors also. So we are investigating evaluation of the leader of genetic factors: the race. But in the same general race population, the risk differences should be adjusted - for example, the African origin varies throughout Africa and what exactly do we mean by 'southeast Asian origin'? This also varies from Japan to Malaysia for example. The same thing can be said about populations at moderate risk. 


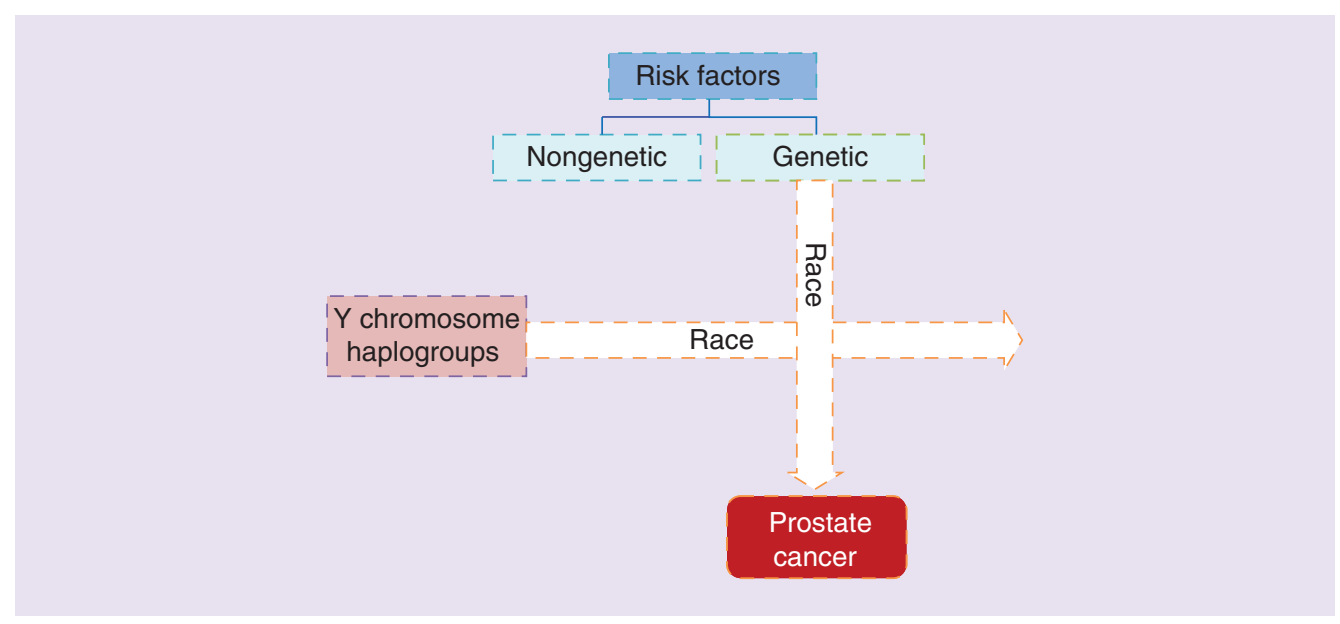

Figure 1. Suggested crossing point between Y-chromosome microsatellites outputs and race as genetic risk of prostate cancer.

Here, we need an accurate ruler to implement ethnic origins as a genetic risk indicator of prostate cancer, and then we need to develop a measurement or system to estimate the genetic risk degrees - in addition to other genetic risk factors - for individuals regardless of their geographical location, or asking about physical characteristics such as color and ethnicity, to avoid mistakes during genetic counseling, diagnosis or therapy. The complexity of prostate cancer genetics is an agreed issue among researchers of genetic risk factors of such tumors. In literature, dozens of polymorphisms have been proved to contribute to developing prostate tumors. In addition, many machine learning prediction studies confirmed the effects of other genes based upon gene expression criteria. However, such researchers also believe race effect is at the source of the genetic risk stream. Having an accurate, detailed ruler to measure for race genetic differences could lead to the successful implementation of an alternative method to evaluate origin as a risk factor.

Since the nonrecombining region of the Y-chromosome had a special interest at the beginning of the millennium, the importance of Y-chromosome markers has increased regarding genealogical reconstruction, molecular archeology, nonhuman primate genetics and human evolutionary studies. Other advantage is low mutation rates of the Y-chromosome nonrecombining region which make it a suitable tool to track paternal lineage and human migration. Biallelic loci and multiallelic loci have been used to explore diversity between individuals and population. Extensive research efforts finally characterized the Y-chromosome markers into haplotypes and haplogroups. Today, we have many national and international databases used for governmental and research purposes [10-12].

Y chromosome microsatellites or Y chromosome short tandem repeats (YSTRs) have been known as a powerful genetic tool in paternity, and genealogical DNA testing. The set of results of YSTRs tested for one individual is called a haplotype, and a haplogroup is a group of similar haplotypes that share a common origin [13,14]. With respect to scientific arguments in some issues of the Y-haplogroups classification, the linkage between race and Y-chromosome haplogroups has previously been studied extensively $[15,16]$. Today it is easy for Y-chromosome microsatellite researchers to distinguish the ethnicities according to haplogroups and the internal branching of haplogroups. This made the analysis of individuals' haplogroups easy to estimate their race and most recent common ancestors. For example, the haplogroup A and B originated from Africa.

Descendants of the Y-DNA haplogroup $\mathrm{C}$ are now spread in southern and eastern Asia, and subhaplogroups are seen in the Americas, islands south of Malaysia, Australia, central Asia and Europe. Y-DNA haplogroup O carriers are thought to be mainly in China in addition to Japanese and Korean populations and the aboriginal Taiwanese, Indonesia, Melanesia, Micronesia and Polynesia. Haplogroup J mostly evolved in the Middle East and spread toward the northwest of Europe, more often found in the Levant region, other parts of the Near East and North Africa. The detailed haplogroups population have been published elsewhere [17-20].

Again by converting ethnic origin instead of PCa genetic risk to the human Y-chromosome DNA haplogroups, the $\mathrm{A}$ and $\mathrm{B}$ haplogroups will be at high risk and $\mathrm{O}$ haplogroup at low risk. It will be useful and able to apply to start from archived - or new $-\mathrm{Y}$ chromosome microsatellite databases, and then this will help for future prediction of the probability of prostate tumor development. However, this needs some further details about accurate subhaplogroups 
and the confusion about the origin of some populations and minorities are still to be discussed. Figure 1 shows the suggested crossing point between Y-chromosome markers analysis outputs and race as a prostate cancer risk factor.

As we suggested above about the core idea, a detailed micro-ruler within the general system can be created to give an accurate hypothetical evaluation of PCa genetic risk.

We suggest here to establish a PCa genetic risk evaluation system using the outputs of Y chromosome marker studies such as populations' haplogroups and individual haplotypes. Exceeding the conventional diagnosis complications, this system could be a useful early diagnostic genetic tool of prostate cancer risk. The suggested system can be measured from 9 to 1 if 10 means confirmed risk and 0 means no risk. Instead of a hypothetical degree of risk degree, the races should be exchanged by related haplogroup/subhaplogroup. The races at high risk such as African-American men which originally belonging to haplogroup A, could take nine degree - or parts of nine in the system suggested above, in contrast, the haplotypes with lowest PCa risk individuals - in theory, southeast Asian men - could take one degree or part of one degree. To establish such a system, two essential parameters are needed: first: the populations which have PCa moderate risk should be leveled correctly in the system suggested. The other parameter is to level the Y chromosome subhaplogroups (haplogroup branching) in the evaluation system. In addition, two recommendations could be presented, first: analysis of Y-chromosome microsatellite markers in men already diagnosed of prostate cancer, targeting more verification of individual's haplotypes, and the second: using Y-chromosome marker-archived databases to implement an initial pairing system between individuals' haplotypes and prostate cancer risk. We need to see more discussions about the correlation between 'race effect' on prostate tumor development and Y-chromosome markers, to facilitate global warning of prostate cancer, one of the most commonly diagnosed cancer in men.

\section{Financial \& competing interests disclosure}

The authors have no relevant affiliations or financial involvement with any organization or entity with a financial interest in or financial conflict with the subject matter or materials discussed in the manuscript. This includes employment, consultancies, honoraria, stock ownership or options, expert testimony, grants or patents received or pending, or royalties.

No writing assistance was utilized in the production of this manuscript.

\section{References}

1. Pernar CH, Ebot EM, Wilson KM, Mucci LA. The epidemiology of prostate cancer. Cold Spring Harb. Perspect. Med. 8(12), pii:a030361 (2018).

2. Walsh PC, Brooks JD. The Swedish prostate cancer paradox. JAMA 277(6), 497-498 (1997).

3. Saika K, Machii R. Incidence rate for prostate cancer in Japanese in Japan and in the United States from the cancer incidence in five continents. Jpn J. Clin. Oncol. 46(11), 1074 (2016).

4. Odedina FT, Akinremi TO, Chinegwundoh F et al. Prostate cancer disparities in black men of African descent: a comparative literature review of prostate cancer burden among black men in the United States, Caribbean, United Kingdom, and West Africa. Infect. Agent. Cancer 4(Suppl. 1), S2 (2009).

5. Beiki O, Ekbom A, Allebeck P, Moradi T. Risk of prostate cancer among Swedish-born and foreign-born men in Sweden, $1961-2004$. Int. J. Cancer 124(8), 1941-1953 (2009).

6. Nair RG. Prostate Cancer in High Risk Population. Temple University, ProQuest LLC, USA (2018).

7. Plata Bello A, Concepcion Masip T. Prostate cancer epidemiology. Arch. Esp. Urol. 67(5), 373-382 (2014).

8. Brawley OW, Barnes S. The epidemiology of prostate cancer in the United States. Semin. Oncol. Nurs. 17(2), 72-77 (2001).

9. Baade PD, Youlden DR, Krnjacki LJ. International epidemiology of prostate cancer: geographical distribution and secular trends. Mol. Nutr. Food Res. 53(2), 171-184 (2009).

10. Ballantyne KN, Goedbloed M, Fang R et al. Mutability of Y-chromosomal microsatellites: rates, characteristics, molecular bases, and forensic implications. Am. J. Hum. Genet. 87(3), 341-353 (2010).

11. Kayser M. The human Y-chromosome - introduction into genetics and applications. Forensic Sci. Rev. 15(2), 77-89 (2003)

12. Calafell F, Larmuseau MHD. The Y chromosome as the most popular marker ingenetic genealogy benefits interdisciplinary research. Hum. Genet. 136(5), 559-573 (2017).

13. Athey TW. Haplogroup prediction from Y-STR values using an allele-frequency approach. J. Genet. Geneal. 1, 1-7 (2005).

14. Kayser M. Forensic use of Y-chromosome DNA: a general overview. Hum. Genet. 136(5), 621-635 (2017).

15. Underhill PA, Shen P, Lin AA, Jin L, Passarino G, Yang WH. Y chromosome sequence variation and the history of human populations. Nat. Genet. 26(3), 358-361 (2000). 
16. Hammer MF. A recent common ancestry for human Y chromosomes. Nature 378(6555), 376-378 (1995).

17. Y Chromosome Consortium. A nomenclature system for the tree of human Y-chromosomal binary haplogroups. Genome Res. 12(2), 339-348 (2002).

18. Jobling MA, Tyler-Smith C. The human Y chromosome: an evolutionary marker comes of age. Nat. Rev. Genet. 4(8), 598-612 (2003).

19. Balanovsky O. Toward a consensus on SNP and STR mutation rates on the human Y-chromosome. Hum. Genet. 136(5), 575-590 (2017).

20. Butler JM. Recent developments in Y-short tandem repeat and Y-single nucleotide polymorphism analysis. Forensic Sci Rev. 15(2), 91-111 (2003). 